\title{
Effects of body size, trophic mode and larval habitat on Diptera stoichiometry: a regional comparison
}

\author{
Peter A. Hambäck, James Gilbert, Katie Schneider, Holly M. Martinson, Gundula Kolb and \\ William F. Fagan
}

P. A. Hambäck (peter.hamback@botan.su.se) and G. Kolb, Dept of Botany, Stockholm Univ., SE-106 91 Stockholm, Sweden. - J. Gilbert, K. Schneider, H. M. Martinson and W. F. Fagan, Dept of Biology, Univ. of Maryland, College Park, MD 20742, USA.

\begin{abstract}
Ecological stoichiometry has emerged as a tool for exploring nutrient demand and evolutionary responses to nutrient limitation. Previous studies of insects have found predictable variability in stoichiometry, both in relation to body size and trophic mode, at ordinal levels or higher. Our study further examines the evolutionary and ecological lability in these traits by comparing the effects of body size, trophic mode (larval and adult) and larval habitat on the stoichiometry of insects within one order (Diptera). The study also expands on previous work by analyzing trophic mode both at coarse (detritivore, herbivore, predator) and fine (high- vs low- nutrient quality resources within trophic categories) scales and by comparing nutrient stoichiometry in two geographical regions, Sweden and Arizona. As predicted, adults feeding on nectar or pollen had the lowest body $\mathrm{N}$ content in the dataset. Additionally, for Diptera with predatory larvae, species low $\mathrm{N}$ diets had lower body $\mathrm{N}$ content than those with high $\mathrm{N}$ diets. However, body $\mathrm{N}$ content was not consistently lower for all species with low $\mathrm{N}$ resources, as species feeding on plant material were indistinguishable in stoichiometry from predators with high $\mathrm{N}$ diets. We suggest that these results emerge because larval resource exploitation is poorly understood in herbivorous Diptera species. Body P content for Swedish Diptera decreased with body size for all trophic modes, and the only difference among trophic modes was that blood feeders had higher P content than other groups. The regional comparison further showed that the allometry of body P content is a labile trait that may vary at regional scales, as there was no allometric scaling of body P content in the Arizona data set, in contrast to the Swedish data set. These results are not easily explained by existing theoretical frameworks, but instead point to a general context-dependence of $\mathrm{P}$ stoichiometry, which should now be a focus for future work.
\end{abstract}

A foundation of ecological stoichiometry is that organisms should evolve to adjust their nutrient demands to the availability of limiting nutrients (Elser et al. 2000c, Baudouin-Cornu et al. 2001, Sterner and Elser 2002, Frost et al. 2005, Kay et al. 2005), suggesting that relative nutrient demands can be explored by comparing chemical composition across taxa (Berendse 1994). Such comparisons have a long history in aquatic and marine sciences, but have only recently been explored among terrestrial insects (Markow et al. 1999, Fagan et al. 2002, Jaenike and Markow 2003, Schade et al. 2003, Woods et al. 2004, Davidson 2005, Martinson et al. 2008). Though these studies suggest that the pattern is perhaps more complex on land, they also show that ecological stoichiometry indeed seems able to explain large-scale variability in the chemical composition of terrestrial insects. First, a broad pattern appearing from previous analyses of published data on the nitrogen $(\mathrm{N})$ content of insects suggests that herbivores have a lower body $\mathrm{N}$ content than predators (Fagan et al. 2002). This lower body $\mathrm{N}$ content of herbivorous insects is suggested to occur because feeding on a less nitrogen-rich food source, such as most plant tissue, has selected against individuals with a high $\mathrm{N}$ demand (Elser et al. 2000a, Jaenike and Markow 2003, Boersma and Elser 2006). Second, smaller species, irrespective of trophic mode, appear to have a higher body P content than larger species (Woods et al. 2004), presumably because the higher growth rate in smaller species puts a higher demand on P-rich ribosomal RNA (Elser et al. 2003, Vrede et al. 2004, Kay et al. 2005, Gillooly et al. 2005).

Previous analyses of terrestrial insects have mainly been performed on literature data consisting of fortuitous collections from a multitude of spatial locations and biomes (but see Fagan and Denno 2004, Woods et al. 2004). As a result, not all insect groups are equally represented, or represented in sufficient numbers for more detailed analyses. Consequently, comparisons have only been possible across broad taxonomic groupings (ordinal levels or higher) and only few studies (Jaenike and Markow 2003, Bertram et al. 2008) have examined variation in both body $\mathrm{N}$ and $\mathrm{P}$ content for terrestrial insects at lower taxonomic levels. Strong selective pressures should have consistent effects across all phylogenetic levels; however, highly related species are much less independent than anciently diverged orders. 
Hence, examining the same general patterns within an insect order is a more conservative test of the evolutionary significance of ecological stoichiometry. We therefore seek to characterize the extent to which stoichiometric signals in trophic level, body size, and phylogeny persist even among closely related taxa. Moreover, we may also expect large differences among sites or biomes in stoichiometric composition, due to differences in nutrient availability, seasonality, and subsequent growth rate limitations (Watts et al. 2006). For instance, Daphnia has higher body P content in regions with a shorter growing season and a concomitant stronger selection for higher growth rate (Elser et al. 2000b, Woods et al. 2003). Such spatial variability, however, cannot be tested in compiled databases for terrestrial insects because taxa have not been collected along large environmental gradients.

In this study, we help fill this important gap by comparing the elemental composition among taxa within the insect order Diptera (flies) between the moist temperate region of southern Sweden (new data) and the dry desert of Arizona (data from Woods et al. 2004). We focus on Diptera for three reasons: 1 ) because of the large variability in trophic mode among Diptera families, both among larvae (including predators, parasites, herbivores, and detritivores) and adults (including nectar feeders, blood feeders, predators and detritivores): 2) because the order includes both terrestrial and aquatic species: and 3) because extensive laboratory studies on Drosophila have wellcharacterized the relationship between stoichiometry and growth (Markow et al. 1999, Jaenike and Markow 2003, Watts et al. 2006). As descriptors of trophic mode we use both larval diet, as the diet during this stage is most closely connected to individual growth rates, and adult diet, as this is the stage that is assayed for stoichiometry. Using the Swedish data set, we examined the variation in $\mathrm{N}$ and $\mathrm{P}$ content with body size, between main trophic modes, and between larval habitats (terrestrial vs aquatic). For $\mathrm{N}$ alone, we subdivided each main trophic mode to investigate further the relationship between species' body $\mathrm{N}$ and the $\mathrm{N}$ content of their main food items. All analyses were performed within a phylogenetic framework using the latest Diptera supertree (Yeates et al. 2006). The Arizona data set is smaller and only contains information on $\mathrm{P}$ content. Hence, in the comparison between geographic data sets, we only examined the allometric and trophic mode variation on P content.

\section{Methods}

The empirical portion of this study included collections of Diptera species from multiple sites within the same nemoral biome of southern Sweden, with the inclusion of three isopod parasitoids (Rhinophoridae and Calliphoridae) collected in Belgium (through Louis Boumans). The primary goal was to include species across a wide array of trophic modes, and to include both aquatic and terrestrial species. These collections resulted in a total of 104 specimens of adult Diptera (Supplementary material Table S1), covering 40 out of 103 Diptera families. All dipterans were classified to main trophic mode based on literature data about larval and adult diet (main sources: Torp 1984,
Sommaggio 1999, Oosterbroek 2006). In a few cases, we excluded specimens where the diet information was not resolved or reliable at the level of identification. This was encountered particularly in the Muscidae and related families, both because they often show large variability among species in diet and because they are, at times, difficult to identify to species. We also pooled nectar and pollen feeders (hereafter floral feeders), due to lack of more specific information. For each species, we recorded the dry body mass $(\mathrm{mg}$ ) and quantified body $\mathrm{C}, \mathrm{N}$ and $\mathrm{P}$ content. For a few species we had limited specimens to analyze all three nutrients, and then substituted a specimen from a closely related and ecologically similar species. In all cases, specimens were starved overnight prior to analysis to minimize diluting effects of gut contents (Fagan et al. 2002). In total, the dataset of Swedish Diptera includes (larval trophic mode) 50 predator/parasite, 13 herbivore, and 41 detritivore species, or (adult trophic mode) 49 floral feeders, 16 detritivores, 4 blood feeders, 16 predators and 15 species that are believed not to feed as adults. The comparative dataset of Woods et al. (2004) from the Sonoran Desert was classified only by larval trophic mode and included only larval detritivores (8) and predators (11) species.

Our analysis suggested a weak association of larval trophic mode with adult body $\mathrm{N}$ content (Results), in contrast to previous studies. Because this trophic signal may have been obscured by large variation in resource stoichiometry within trophic categories, we subdivided the predator and detritivore groups for the $\mathrm{N}$-analysis based on more specific diet information (fine trophic mode). A similar subdivision of herbivore species was not possible due to a low sample size and because diets were quite similar among species. Adult trophic modes were not further subdivided.

Species with predatory larvae were subdivided into two fine trophic modes, based on the average $\mathrm{N}$ content of their main food items. The group of predators feeding on a low $\mathrm{N}$ diet included species attacking aphids $(6.6 \% \mathrm{~N}$; Syrphidae and Chloropidae), leafhoppers (9.3\% N; Pipunculidae) and isopods (7.1\% N; Rhinophoridae). These prey items are $\mathrm{N}$-poor when compared with the average body $\mathrm{N}$ content of arthropods, at $10.5 \%$ (data from Fagan et al. 2002, Martinson et al. 2008). The predator group with a high $\mathrm{N}$ diet included species feeding primarily on insect larvae, gastropods (10-11\% N; Sciomyzidae), lumbricids (10-12\% N; Calliphoridae: Bellardia sp.), or vertebrates (Calliphoridae, Hippoboscidae) during their larval stage. Species with detritivorous larvae were subdivided into two fine trophic modes, based on whether larvae feed on plant detritus or on microorganisms within litter. Species known to feed on microorganisms are mainly aquatic (Chironomidae, Culicidae, Ephydridae, some Stratiomyidae), but also include the terrestrial family Lauxaniidae.

Phosphorus content (\% P, dry mass basis) was assayed using persulfate digestion and ascorbate-molybdate colorimetry (APHA 1992). Due to the size range of individual insects, animals were prepared for analysis based on the methods described in Woods et al. (2004). Small insects (smaller than about $0.5 \mathrm{mg}$ dry mass) were analyzed whole in reduced volumes of reagents. Insect of intermediate size were crushed lightly, reweighed, and assayed whole. Large insects (greater than about $10 \mathrm{mg}$ dry mass) were ground 
using a mortar and pestle and subsamples (1-3 mg) were assayed. Nitrogen and carbon content $(\% \mathrm{~N}, \% \mathrm{C}$, dry mass basis) was assayed by using an elemental analyzer. In this analysis, samples were oxidized and reduced to $\mathrm{N}_{2}$ and $\mathrm{CO}_{2}$, respectively, which were measured with a thermal conductivity detector and IR-detection. Before analysis, samples were prepared as for the phosphorus analysis.

To analyze stoichiometric data incorporating phylogenetic information, we used the latest supertree of Diptera from the FlyTree project (Yeates et al. 2006). The supertree was trimmed to retain only families for which we had specimens, while keeping the branch lengths as in the full tree. For families with multiple representatives, species were positioned at a common level below the family node.

All phylogenetically controlled models were analyzed using the ape package in R 2.4.1 (Paradis et al. 2004); our analyses made use of a modified generalized least squares method (GLS, Martins and Hansen 1997). Statistical independence among data points is a requirement of ordinary least squares regression (OLS) models; with comparative species data, this would be analogous to a star phylogeny with all species equally related to each other. However, species related by a branching pattern of evolution are not independent, since any two species share an identical evolutionary history up to their common ancestor. GLS methods account for this non-independence. Instead of assuming that all data points are drawn from the same normally distributed population, as in OLS, GLS methods assume that data points are drawn from different normally distributed populations, but that the variances of these populations covary by a measure of distance along branches of the phylogeny. These relations can be described by a variance-covariance matrix that is estimated using the set of all pairwise distances between species along the phylogeny. This matrix is incorporated into the error term of a linear model. Thus, for each species there is a unique value for the error variance which has been calculated with reference to the species' position in the phylogenetically structured dataset. We assumed that the covariance between species in the matrix decayed exponentially with phylogenetic distance, which is appropriate for models of stabilizing selection (Hansen and Martins 2006). This requires an extra parameter, the exponent of decay in covariance $(\alpha)$, to be estimated, where a large $\alpha$ indicates rapid decay in species covariance, and hence little phylogenetic dependence. To interpret $\alpha$ quantitatively requires phylogenetic branch lengths to be known. An alternative assumption of linear decay in covariance, typical of fluctuating selection or random genetic drift (Hansen and Martins 2006), explained less variance in our data and is not discussed further. When fitting models, we used a backwards stepwise approach, fitting the full model and simplifying it by removing predictor variables and their interactions when a likelihood ratio test statistic (distributed as $\chi^{2}$ ) indicated that these terms did not improve the model.

Complete CNP data were available for a subset of species (Supplementary material Table S1). To investigate correlations among variables, which might confound subsequent analyses, we first examined a correlation matrix of phylogenetically independent contrasts (Felsenstein 1985, Garland et al. 1992) in C, N and P, checking the results using GLS regression models of each against each other. The results suggested that $\mathrm{C}$ and $\mathrm{N}$ covary, but that $\mathrm{P}$ varies independently of both (Table 1). Hence, we split subsequent analyses, investigating $\mathrm{C}: \mathrm{N}$ ratios and $\mathrm{N}$ content independently of C:P ratios and $\mathrm{P}$ content. However, in every model we examined, the analysis for $\mathrm{C}$ :nutrient ratios gave similar statistical results as that for nutrients (see Supplementary material Table S2 and Table S3 for statistical analysis of C:nutrient ratios). Before testing complete models, we investigated whether body $\mathrm{P}$ and $\mathrm{N}$ were phylogenetically dependent by comparing the deviance of a GLS model using the observed data with that of 1000 models with the response variable randomly reshuffled among taxa as recommended by Blomberg et al. (2003).

We then constructed a GLS model of body $\mathrm{N}$ and P content as well as the C:N and C:P ratios, using larval trophic mode, adult trophic mode and body size as predictive variables, plus their interactions. To fit an interaction between larval trophic mode and adult trophic mode, we grouped larval detritivores and herbivores since there was only one representative with herbivorous larvae and non-floral feeding adults. We carried out a further $\mathrm{N}$ analysis using fine larval trophic mode, adult trophic mode and body size. Finally, we compared body P content between the datasets from Sweden and Arizona. The Arizona dataset included no herbivorous Diptera, so this analysis included only predators and detritivores. The GLS model therefore included trophic mode (predator and detritivore), body size (dry mass), and region (Arizona and Sweden).

\section{Results}

There was large variability in stoichiometric composition among Diptera species (Supplementary material Table S1). The body N content varied from $6.6 \%$ in Caenia fumosa (Ephydridae), a species with aquatic microbial feeding larvae, to $13.8 \%$ in Empis pennipes (Empididae), a species with predatory larvae. The body $\mathrm{P}$ content varied from $0.3 \%$ in Pherbina coryleti (Sciomyzidae), a species with snail parasitic larvae, to $1.7 \%$ in Aedes spp. (Culicidae), with microbial feeding larvae. Variance in body $\mathrm{N}$ content showed a significant phylogenetic component; only $0.7 \%$ of the reshuffled models had lower deviance than our phylogenetic model. Body P content, on the other hand, showed a lower degree of phylogenetic dependence: $25 \%$ of models based on the reshuffled data sets had a lower deviance than the observed data.

Table 1. Correlation matrix of independent contrasts in $\mathrm{C}, \mathrm{N}$ and $\mathrm{P}$ content, where complete data were available $(n=51)$. Upper right: pairwise correlation coefficients between phylogenetically independent contrasts for each variable (in brackets, correlation coefficient for raw data). Lower left: slope coefficients of phylogenetic GLS models of $\mathrm{N}$ and $\mathrm{P}$ (rows) using $\mathrm{C}$ and $\mathrm{N}$ (columns) as predictor variables. Key: ${ }^{\text {ns }}$, not significant; ${ }^{* * *}, \mathrm{p}<0.001$.

\begin{tabular}{lccc}
\hline & $\% \mathrm{C}$ & $\% \mathrm{~N}$ & $\% \mathrm{P}$ \\
\hline$\% \mathrm{C}$ & - & $0.56(0.43)$ & $0.18(0.05)$ \\
$\% \mathrm{~N}$ & $0.18^{* * *}$ & - & $0.02(-0.09)$ \\
$\% \mathrm{P}$ & $0.001^{\mathrm{ns}}$ & $-0.63^{\mathrm{ns}}$ & - \\
\hline
\end{tabular}


In the analysis of coarse trophic modes on body $\mathrm{N}$ content, we found that flies could be grouped into two categories of adult trophic mode that differed in body stoichiometry: floral feeders and other consumers (comparing model with all adult trophic modes vs model with condensed trophic modes, likelihood ratio $[\mathrm{LR}]=4.8$, $\mathrm{DF}=6, \mathrm{p}=0.6$ ). Samples were also grouped by coarse larval trophic mode into predator and non-predator to facilitate modeling the interaction between adult and larval trophic modes (Methods). Although there was no three-way interaction between the predictor variables, there was a strong two-way interaction between adult and larval trophic mode on body $\mathrm{N}$, indicating that body $\mathrm{N}$ content is associated with ontogeny of feeding mode (dropping 'adult $\times$ larval trophic mode', $\mathrm{LR}=9.5, \quad \mathrm{DF}=1, \quad \mathrm{p}<$ 0.005). Among species with floral feeding adults, those with predatory larvae had much lower body $\mathrm{N}$, while among non-floral feeders, species with predatory larvae had higher body $\mathrm{N}$ (Fig. 1).

To study all the trophic modes for the flies in our data set, we investigated the main effects of larval and adult trophic modes, removing their interaction. Both adult and larval trophic modes affected the allometric slope of body $\mathrm{N}$ content (Table 2a, Fig. 2). Species with floral-feeding adults and predatory larvae had a negative allometry of body $\mathrm{N}$ content (Fig. 2a), whereas species with non-floral feeding adults and non-predatory larvae had a positive allometry (Fig. 2b). Both larval and adult trophic modes influenced body $\mathrm{N}$ in the absence of these interactions (dropping 'larval trophic mode', $\mathrm{LR}=7.9, \mathrm{DF}=2, \mathrm{p}=0.02$; dropping 'adult trophic mode', $\mathrm{LR}=9.1, \mathrm{DF}=1, \mathrm{p}=0.003$ ), whereas the effect of body size was not significant ( $L R=$ $0.4, \mathrm{DF}=1, \mathrm{p}=0.5)$. Species with predatory larvae had a lower body $\mathrm{N}$ content than other groups, and species with adult floral feeders had a lower body $\mathrm{N}$ content than other groups.

Because there were few $(n=2)$ aquatic dipterans with predatory larvae, we constructed a model using only nonpredatory larvae to investigate the importance of larval habitat. Neither larval habitat $(\mathrm{LR}=0.12, \mathrm{DF}=1, \mathrm{p}=0.7)$

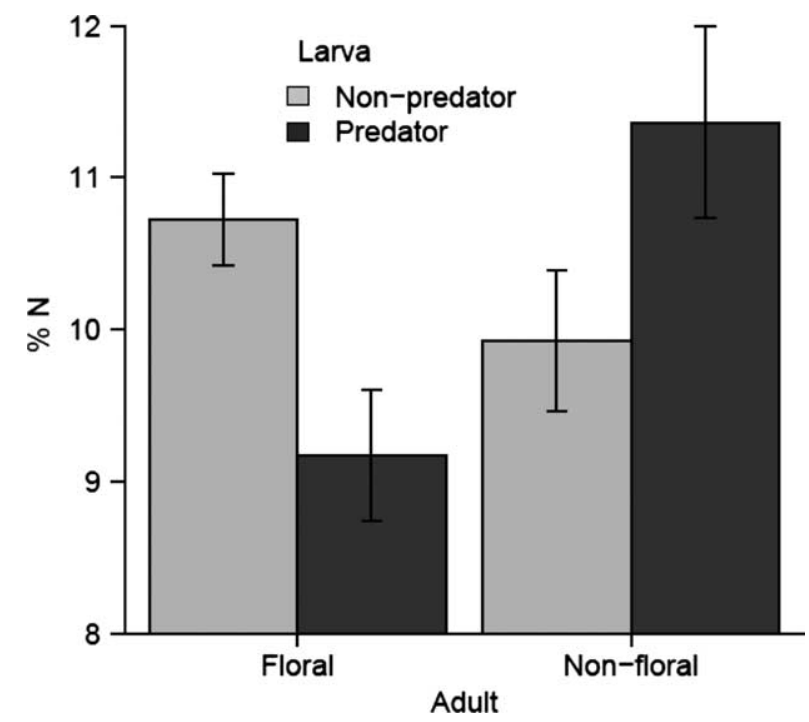

Figure 1. Body N-content of insects with different ontogenies of feeding mode. Standard errors are from the phylogenetic model. nor any interaction involving this term (adult trophic mode $\times$ larval habitat, $\mathrm{LR}=0.02, \mathrm{DF}=1, \mathrm{p}=0.9$; body size $\times$ larval habitat, $\mathrm{LR}=1.8, \mathrm{p}=0.19)$ explained a significant proportion of the variance in $\mathrm{N}$, and larval habitat was not modeled further.

In the analysis of fine trophic modes on body $\mathrm{N}$ content (Table $2 \mathrm{~b}$ ), we found that the larval trophic modes could be grouped into four categories that differed in body stoichiometry: (1) microbial feeders, (2) predators with low $\mathrm{N}$ diet, (3) predators with high $\mathrm{N}$ diet, and (4) species feeding on live or dead plant biomass (hereafter plant feeders; comparing model with all larval trophic modes versus model with condensed trophic modes, $\mathrm{LR}=1.4$, $\mathrm{DF}=4$, $\mathrm{p}=0.8)$. Here, as in the coarse analysis, $\mathrm{N}$ content was best described by both larval and adult trophic modes, plus the two-way interaction of each with body size (Table 2b). The interaction of larval trophic mode and body size was only marginally significant and arose because body $\mathrm{N}$ content decreased with body size mainly for predators with high $\mathrm{N}$ diet. In addition, overall body $\mathrm{N}$ content was lower for predators with low $\mathrm{N}$ diet relative to other trophic modes. Specifically, the predatory species with low $\mathrm{N}$ diets had the lowest body $\mathrm{N}$ content, almost $2 \%$ (absolute percent) lower than predatory species with a high $\mathrm{N}$ diet. Larval habitat was not significant $(\mathrm{LR}=1.6, \mathrm{DF}=1, \mathrm{p}=0.21)$ and was excluded from the analysis.

In the analysis of $\mathrm{P}$ content, we again found an association with feeding ontogeny (dropping 'adult $\times$ larval trophic mode', $\mathrm{LR}=3.9, \mathrm{DF}=1, \mathrm{p}<0.05)$. Adults feeding on vertebrate blood had higher body P content than other groups, which were not different. Excluding these species, the interaction was only marginally significant (dropping 'adult $\times$ larval trophic mode', $\mathrm{LR}=3.6, \mathrm{DF}=1$, $\mathrm{p}=0.06$ ). Adult body $\mathrm{P}$ content was also strongly and negatively related to body size (Table 3 , Fig. 3). Larval habitat was not significant (dropping 'larval habitat', LR = $0.8, \mathrm{DF}=2, \mathrm{p}=0.4)$, and there was no effect of larval trophic mode on body P (dropping 'larval trophic mode', $\mathrm{LR}=2.2, \mathrm{DF}=2, \mathrm{p}=0.3)$. No interactions were significant. We did not test for an interaction between larval trophic mode and larval habitat owing to a lack of aquatic herbivores $(n=0)$ and aquatic predators $(n=2)$ in the dataset. Fig. $4 \mathrm{~b}$ shows the common allometric scaling of body $\mathrm{P}$ content for four families well-represented in the database.

The comparison of $\mathrm{P}$ content between Sweden and Arizona included only detritivores and predators, as the Arizona dataset lacked herbivores. The interaction between body size and region was highly significant (Table 4). There was no allometric scaling of body P content in the Arizona data set, whereas the allometry was strongly negative for the Swedish flies (Fig. 4). Body P content was higher for small species and lower for large species in the Swedish data set as compared with the Arizona data set. Body P content was also higher for detritivores than for predators (Table 4).

\section{Discussion}

This analysis is unique in three aspects. First, this study examined the role of trophic mode, larval habitat, and body size on the stoichiometry of insects at a taxonomic level 
Table 2. Statistical models describing body $\mathrm{N}$ content, for all specimens with (a) coarse trophic mode description $(\alpha=0.70)$ or (b) fine trophic mode description $(\alpha=54.4)$, with phylogenetic information (GLS). Key: Tro, larval trophic mode; TroAd, adult trophic mode; BS, body size ( $\log _{\mathrm{e}}$-transformed).

(a) Nitrogen, coarse trophic mode

\begin{tabular}{|c|c|c|c|c|}
\hline Model & Lik. ratio & $\Delta \mathrm{DF}$ & $\mathrm{p}$ & $\triangle \mathrm{AIC}$ \\
\hline $\mathrm{BS} \times$ Tro & 8.43 & 1 & 0.016 & 3.14 \\
\hline $\mathrm{BS} \times$ TroAd & 5.72 & 1 & 0.015 & 2.00 \\
\hline Table of coefficients & Estimate & SE & & \\
\hline Intercept (detritivore, floral feeder) & 10.54 & 0.49 & & \\
\hline BS & -0.001 & 0.27 & & \\
\hline Tro (herbivore) & 0.18 & 0.70 & & \\
\hline Tro (predator) & 0.08 & 0.47 & & \\
\hline TroAd (other) & -0.05 & 0.48 & & \\
\hline BS $\times$ Tro (herbivore) & -0.80 & 0.76 & & \\
\hline BS $\times$ Tro $($ predator $)$ & -0.63 & 0.26 & & \\
\hline BS $\times$ TroAd (other) & 0.70 & 0.29 & & \\
\hline \multicolumn{5}{|l|}{ (b) Nitrogen, fine trophic mode } \\
\hline Model & Lik. ratio & $\Delta \mathrm{DF}$ & $\mathrm{p}$ & $\triangle \mathrm{AIC}$ \\
\hline BS $\times$ TroAd & 8.10 & 1 & 0.004 & 6.10 \\
\hline $\mathrm{BS} \times$ Tro & 7.16 & 3 & 0.067 & 1.16 \\
\hline Table of coefficients & Estimate & SE & & \\
\hline Intercept (predator:high $\mathrm{N}$, floral feeder) & 11.31 & 0.46 & & \\
\hline BS & -0.83 & 0.26 & & \\
\hline Tro (detritivore:plant material) & -0.32 & 0.45 & & \\
\hline Tro (detritivore:microbial feeder) & -1.97 & 0.49 & & \\
\hline Tro (predator:low N) & -2.24 & 0.64 & & \\
\hline TroAd (other) & 0.03 & 0.43 & & \\
\hline BS ×Tro (detritivore:plant material) & 0.58 & 0.25 & & \\
\hline BS $\times$ Tro (detritivore:microbial feeder) & 0.78 & 0.52 & & \\
\hline BS $\times$ Tro $($ predator:low $\mathrm{N})$ & 0.52 & 0.44 & & \\
\hline BS $\times \operatorname{TroAd}($ other) & 0.69 & 0.26 & & \\
\hline
\end{tabular}

much finer than most previous analyses (but see Jaenike and Markow 2003). A fine-scale phylogenetic analysis has a higher chance of detecting lability in body $\mathrm{N}$ and $\mathrm{P}$ content, and is also less susceptible to the confounding effects of convergent evolution across major lineages than is a broader analysis with fewer data for each taxonomic group. Placed in the context of studies performed at finer (Jaenike and Markow 2003) or coarser (Fagan et al. 2002, Woods et al. 2004, Martinson et al. 2008) taxonomic scales, it becomes apparent that nitrogen and phosphorus contents are labile at several levels of taxonomic resolution. Second, this study involved a group of holometabolous insects that change diet with life stage, whereas earlier studies have included diet information during only one life stage (but see Raubenheimer and Simpson 1997). Third, this study compared the allometry of body $\mathrm{P}$ content for Diptera between two geographically distant regions, whereas most previous studies are based either on fortuitous collections of specimens (Elser et al. 2000a, 2003, Fagan et al. 2002) or have compared taxa within a single region (Cross et al. 2003, Fagan and Denno 2004, Woods et al. 2004) or in two similar regions (Evans-White et al. 2005, but see Woods et al. 2003). In this cross-region comparison, we identified allometric variation in insect $\mathrm{P}$ content that differs among major biomes. These novel aspects of the study challenge some previous conclusions and lead to new avenues of investigation into the ecological stoichiometry of insects.

Although body $\mathrm{N}$ content varied with both larval and adult trophic modes, $\mathrm{N}$ content did not directly reflect the nutritional quality of the resource. As expected, predator species feeding as larvae on high-N prey (insects and vertebrates) had the highest body $\mathrm{N}$ content; however, herbivores, with $\mathrm{N}$-poor diets, were similar to predators with high-N diets. This finding disagrees with an emerging trend in the literature for consumer-resource correspondence in N content (Fagan et al. 2002, Sterner and Elser 2002, Jaenike and Markow 2003, Martinson et al. 2008). For instance, Fagan et al. (2002) found that predatory insects tend to have higher $\mathrm{N}$ content than herbivores, but their sample of Diptera was small, and biased towards Drosophilidae, a low N family (6-9\% N). Moreover, their analysis combined Diptera and Lepidoptera into 'Panorpida', potentially obscuring important variation (especially given the phylogenetic dependence we have identified in $\mathrm{N}$ content). We also observed that body $\mathrm{N}$ content varied allometrically for some trophic modes. Allometry in body $\mathrm{N}$ content was not observed in previous studies (Fagan et al. 2002), but these analyses did not examine variability among trophic modes in $\mathrm{N}$ allometry. This variability in $\mathrm{N}$ allometries is an interesting pattern that needs further exploration.

The expectation for adult diets is less clear, as adult diets in a holometabolous species mainly affect basal metabolism and sexual reproduction (Raubenheimer and Simpson 1997). Nevertheless, this study suggests that adult diet reflects body $\mathrm{N}$ content in that species feeding on nectar or pollen had a lower body $\mathrm{N}$ content. Our analysis also suggests that the larval and adult trophic modes have interactive effects on body $\mathrm{N}$ content. This may have occurred because larval and adult diets were correlated in 


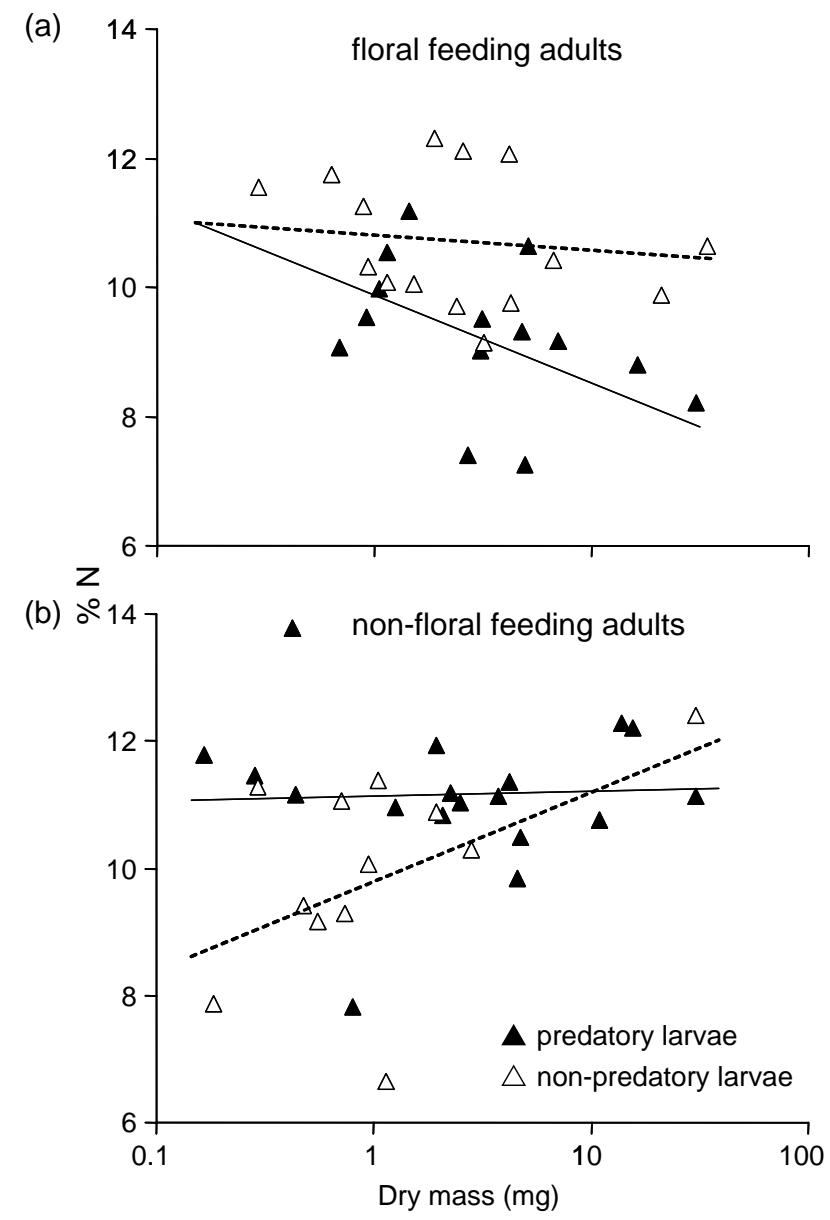

Figure 2. Semi-log plot of body $\mathrm{N}$ content (\% $\mathrm{N}$ by dry mass) as a function of body mass for (a) floral-feeding and (b) non-floral feeding adults. Notice that the values on the $\mathrm{x}$-axis in this and subsequent figures refer to actual weights.

the data set at a finer scale than we could analyze. Diptera species feeding on low $\mathrm{N}$ prey as larvae often feed on nectar or pollen as adults (e.g. Syrphidae, Rhinophoridae), while species feeding on high $\mathrm{N}$ prey as larvae are often also predatory as adults (e.g. Empididae, Dolichopodidae, Asilidae). These correlations raise the question of how much adult body stoichiometry is constrained by larval resource stoichiometry, but data on this issue is currently quite limited. It is also possible that the high mobility of dipteran adults, compared with larvae, make them more

Table 3. Statistical model describing body $\mathrm{P}$ content for all specimens with a coarse trophic mode description, with phylogenetic information (GLS, $\alpha=11.1$ ). Key as in Table 2.

\begin{tabular}{lrlcc}
\hline Model & Lik. ratio & $\Delta \mathrm{DF}$ & $\mathrm{p}$ & $\Delta$ AIC \\
\hline BS & 13.80 & 1 & $<0.001$ & 11.80 \\
TroAd & 26.12 & 4 & $<0.001$ & 18.11 \\
Table of coefficients & Estimate & SE & & \\
Intercept (blood feeder) & 1.61 & 0.14 & & \\
BS & -0.08 & 0.02 & & \\
TroAd (detritivore) & -0.61 & 0.16 & & \\
TroAd (floral feeder) & -0.83 & 0.14 & & \\
TroAd (non-feeding adult) & -0.62 & 0.16 & & \\
TroAd (predator) & -0.68 & 0.15 & & \\
\hline
\end{tabular}
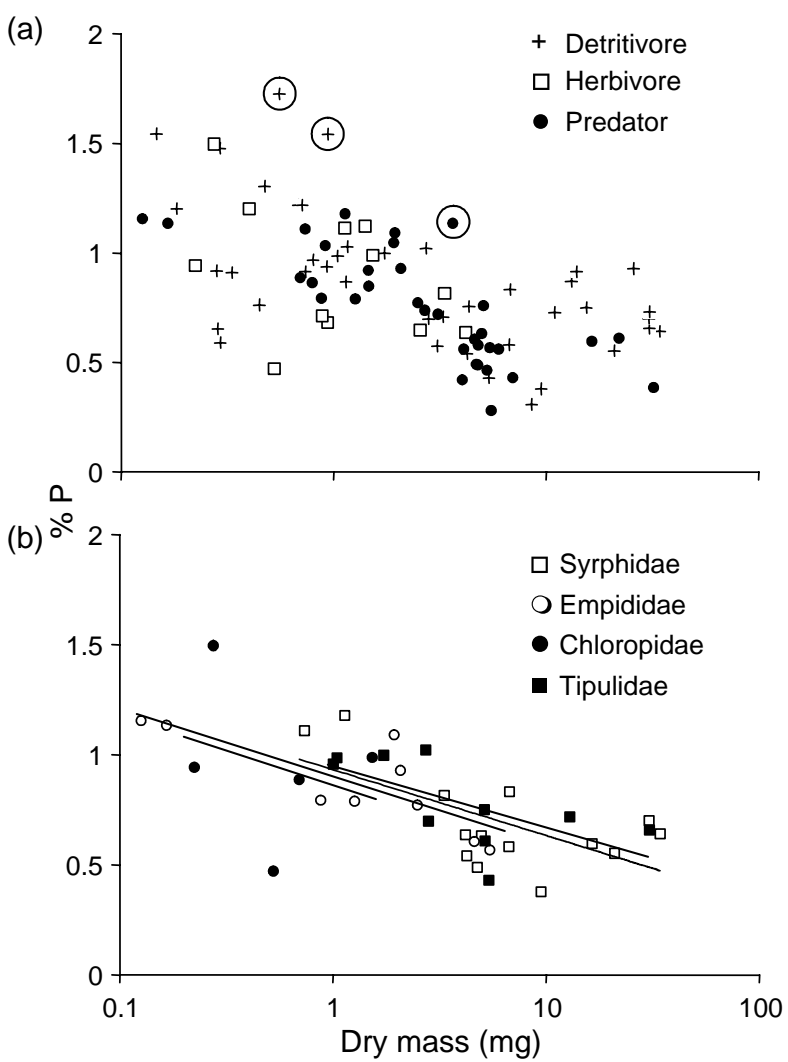

Figure 3. Semi-log plot of body P content (\% P by dry mass) as a function of (a) body mass and larval trophic mode for 87 Diptera species and (b) body mass for four families and groups of related families (Syrphidae: 14 species; Empididae/Dolichopodidae/Hybotidae: 9 species; Chloropidae: 5 species; Tipulidae/Limoniidae: 10 species). Three blood feeding species, with different larval feeding modes, are circled in (a), as this group was significantly different than other adult trophic modes (Table 3). Lines in (b) represent least square fits within each group (not significantly different).

able to adjust for stoichiometric mismatches through selective foraging, reducing the necessity for changes in body stoichiometry from larvae to adult.

If our results on body $\mathrm{N}$ content are more representative for Diptera than previous studies, why were herbivorous Diptera in our sample so high in N, and is there a weaker consumer-resource correspondence in this order than in other arthropods? The latter does not seem to be the general case as Jaenike and Markow (2003) reported a tight relationship between larval resource $\mathrm{N}$ and adult $\mathrm{N}$ in Drosophila species. Further, predatory Diptera feeding on low $\mathrm{N}$ prey (aphids, leafhoppers and isopods) had a lower body $\mathrm{N}$ content than those feeding on high $\mathrm{N}$ prey. The high body $\mathrm{N}$ content of herbivorous Diptera, in relation to the lower body $\mathrm{N}$ content of predators feeding on low $\mathrm{N}$ prey, is still puzzling, even though most herbivore species in this study feed on relatively high N plants (e.g. Delia floralis on cabbage, several chloropids on cereals). However, the low $\mathrm{N}$ content of plant material depends on the carbon rich structures in plant cell walls, and this material may be relatively easy for insect herbivores to egest or avoid in comparison to $\mathrm{N}$ poor structures in aphids and other low $\mathrm{N}$ prey (Fink and Von Elert 2006). Another possibility is that 


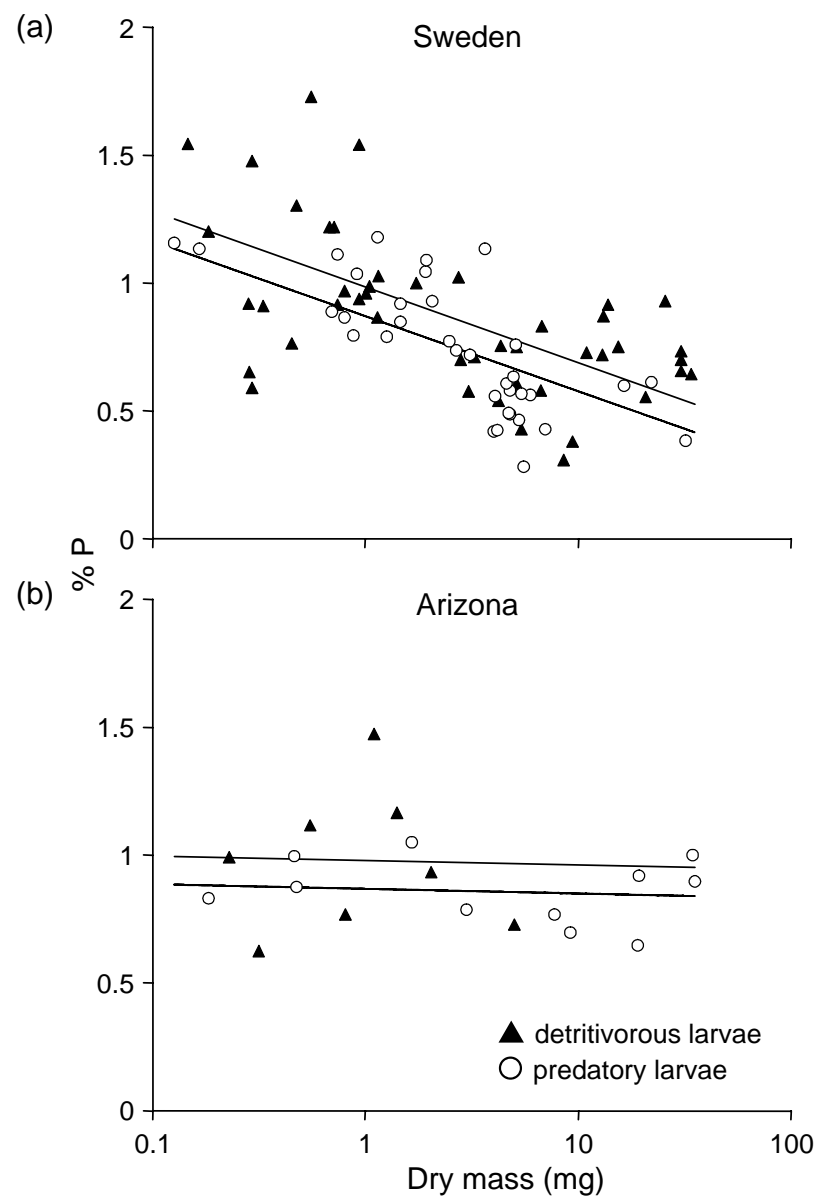

Figure 4. Semi-log plot of body P content (\% P by dry mass) as a function of body mass and larval trophic mode for 99 Diptera species within the Swedish (a) and Arizona (b) data sets. Lines represent phylogenetically controlled least square fits from the overall analysis.

species differ in their ability to forage selectively among prey and in their ability for post-ingestive regulation (Raubenheimer and Simpson 1997). Studies on invertebrate predators (carabids and spiders) show that mobile species have an ability to select diets to optimise nutritional composition whereas less mobile species compensate for

Table 4. Statistical model describing body $\mathrm{P}$ content for combined Sweden and Arizona samples, with phylogenetic information (GLS, $\alpha=72.6)$. Key: Tro, trophic mode; BS, body size (loge-transformed); Reg, region.

\begin{tabular}{lcccc}
\hline Model & Lik. ratio & $\Delta \mathrm{DF}$ & $\mathrm{p}$ & $\Delta \mathrm{AIC}$ \\
\hline Tro & 5.91 & 1 & 0.015 & 5.92 \\
BS: Reg & 11.61 & 1 & $<0.001$ & 0.23 \\
& & & & \\
Table of coefficients & Estimate & SE & & \\
Intercept (detritivore, & 0.98 & 0.06 & & \\
$\quad$ Arizona) & & & & \\
Tro (predator) & -0.11 & 0.05 & & \\
BS & -0.01 & 0.03 & & \\
Reg (Sweden) & 0.001 & 0.06 & & \\
BS:Reg (Sweden) & -0.12 & 0.04 & & \\
\hline
\end{tabular}

nutritional imbalances by selective extraction from ingested prey items (Mayntz et al. 2005, Raubenheimer et al. 2007). Many dipteran larvae have low mobility, essentially living inside their own food, and may therefore have a fairly limited capacity for selective foraging. More studies are clearly needed to distinguish among these alternatives.

Another surprising result from our analysis was the different allometric scaling of body $\mathrm{P}$ content between geographic regions. Small species in the Swedish data set had higher P content than small species in the Arizona data set, whereas large species in the Arizona data set had higher $\mathrm{P}$ content than large species in the Swedish data set. The only previous studies that have compared body $\mathrm{P}$ content across large spatial scales found that poikilothermic organisms (plants, animals and microorganisms) had higher body $\mathrm{P}$ in colder environments (Elser et al. 2000b, Woods et al. 2003). Part of the difference between regions could be explained by temperature. In colder environments, poikilotherms in general tend to have lower metabolic rates, but also higher P (Addo-Bediako et al. 2002, Woods et al. 2003, Clarke and Fraser 2004). Although heavily debated (Clarke 2004, 2006, Clarke and Fraser 2004, Gillooly et al. 2006), an emerging metabolic theory of ecology attempts to connect these processes mechanistically. Gillooly et al. (2001) modeled variation in development time with body size and temperature, and noted that a large part of the unaccounted variance was explained by species-specific variability in the C:P ratio of individuals. This may be due to allometric variation in demand for $\mathrm{P}$ in RNA (relatively size-variant) and outside of RNA (relatively sizeinvariant; Gillooly et al. 2005). Thus it may be that colder climates exert a selective pressure on $\mathrm{P}$ content through body size and/or development time, although theory is currently in its infancy and predictions are difficult to make.

In addition, adaptation to cold environments may specifically require $\mathrm{P}$ rich compounds in freezing tolerance (Woods et al. 2003), or may indirectly increase body $\mathrm{P}$ through increasing RNA (and hence protein) levels to compensate for reduced metabolic rates. RNA and P content have been linked through the Growth Rate Hypothesis (Elser et al. 2000c), with considerable empirical support (Elser et al. 2003, Woods et al. 2003, 2004, Perkins et al. 2004, Gillooly et al. 2005). However, the existence of such metabolic cold adaptations is highly controversial (Clarke 2006), and comparative analyses have suggested that evolutionary adaptations to temperature may explain only a minor part of the temperature-related variability in metabolism for insects (Addo-Bediako et al. 2002, Gillooly et al. 2006).

In conclusion, our results broadly support existing findings in that $\mathrm{N}$ content varied with trophic groups, while $\mathrm{P}$ content was largely a decreasing function of body size. However, through a finer scale analysis than previously attempted, and with a cross-regional comparison, we were able to identify two surprising results. First, Diptera body N did not directly increase with the quality of their diet. To explain variation in body $\mathrm{N}$, therefore, broad trophic groups such as 'predator' and 'detritivore' may not be sufficient, and rigorous studies are now needed that relate consumer quality to the actual resource quality of a species. Second, allometric trends in body $\mathrm{P}$ varied across regions. Hence, a generally negative allometric trend in body $\mathrm{P}$ 
cannot be a priori assumed; environmental factors such as temperature and seasonality may interact with selection on growth rates in different regions to produce different patterns. Our results are not easily explained by existing theoretical frameworks, but instead point to a general context-dependence of $\mathrm{P}$ stoichiometry, which should now be a focus for future work. Finally, these responses in $\mathrm{N}$ and $\mathrm{P}$ should preferentially be integrated at the level of individuals, where other physiological and ecological adaptations may affect the selective forces acting on body stoichiometry.

Acknowledgements - Kavita Isvaran was very helpful in advising on the appropriate statistical model. This paper is one product of the Spatial Stoichiometry working group at the National Center for Ecological Analysis and Synthesis, a center funded by the National Science Foundation, the Univ. of California, and the State of California. Funding was also provided by the Swedish Research Council FORMAS (to PAH).

\section{References}

Addo-Bediako, A. et al. 2002. Metabolic cold adaptation in insects: a large-scale perspective. - Funct. Ecol. 16: 332-338.

APHA 1992. Standard methods for the examination of water and wastewater (18th ed.). - Am. Public Health Ass. - Washington DC.

Baudouin-Cornu, P. et al. 2001. Molecular evolution of protein atomic composition. - Science 293: 297-300.

Berendse, F. 1994. Competition between plant populations at low and high nutrient supplies. - Oikos 71: 253-260.

Bertram, S. et al. 2008. Extensive natural intraspecific variation in stoichiometric (C:N:P) composition in two terrestrial insect species. - J. Insect Sci. 8: 26.

Blomberg, S. P. et al. 2003. Testing for phylogenetic signal in comparative data: behavioral traits are more labile. - Evolution 57: 717-745.

Boersma, M. and Elser, J. J. 2006. Too much of a good thing: on stoichiometrically balanced diets and maximal growth. - Ecology 87: 1325-1330.

Clarke, A. 2004. Is there a universal temperature dependence of metabolism? - Funct. Ecol. 18: 252-256.

Clarke, A. 2006. Temperature and the metabolic theory of ecology. - Funct. Ecol. 20: 405-412.

Clarke, A. and Fraser, K. P. P. 2004. Why does metabolism scale with temperature? - Funct. Ecol. 18: 243-251.

Cross, W. F. et al. 2003. Consumer-resource stoichiometry in detritus-based streams. - Ecol. Lett. 6: 721-732.

Davidson, D. W. 2005. Ecological stoichiometry of ants in a New World rain forest. - Oecologia 142: 221-231.

Elser, J. J. et al. 2000a. Nutritional constraints in terrestrial and freshwater food webs. - Nature 408: 578-580.

Elser, J. J. et al. 2000b. The evolution of ecosystem processes: growth rate and elemental stoichiometry of a key herbivore in temperate and arctic habitats. - J. Evol. Biol. 13: 845-853.

Elser, J. J. et al. 2000c. Biological stoichiometry from genes to ecosystems. - Ecol. Lett. 3: 540-550.

Elser, J. J. et al. 2003. Growth rate-stoichiometry couplings in diverse biota. - Ecol. Lett. 6: 936-943.

Evans-White, M. A. et al. 2005. Taxonomic and regional patterns in benthic macroinvertebrate elemental composition in streams. - Freshwater Biol. 50: 1786-1799.
Fagan, W. F. and Denno, R. F. 2004. Stoichiometry of actual vs potential predator-prey interactions: insights into nitrogen limitation for arthropod predators. - Ecol. Lett. 7: 876-883.

Fagan, W. F. et al. 2002. Nitrogen in insects: implications for trophic complexity and species diversification. - Am. Nat. 160: 784-802.

Felsenstein, J. 1985. Phylogenies and the comparative method. - Am. Nat. 125: 1-15.

Fink, P. and Von Elert, E. 2006. Physiological responses to stoichiometric constraints: nutrient limitation and compensatory feeding in a freshwater snail. - Oikos 115: 484-494.

Frost, P. C. et al. 2005. Are you what you eat? Physiological constraints on organismal stoichiometry in an elemenatally imbalanced world. - Oikos 109: 18-28.

Garland, T. et al. 1992. Procedures for the analysis of comparative data using phylogenetically independent contrasts. - Syst. Biol. 42: $265-292$.

Gillooly, J. F. et al. 2001. Effects of size and temperature on metabolic rate. - Science 293: 2248-2251.

Gillooly, J. F. et al. 2005. The metabolic basis of whole-organism RNA and phosphorus content. - Proc. Natl Acad. Sci. USA 102: 11923-11927.

Gillooly, J. F. et al. 2006. Response to Clarke and Fraser: effects of temperature on metabolic rate. - Funct. Ecol. 20: 400-404.

Hansen, T. F. and Martins, E. P. 2006. Translating between microevolutionary process and macroevolutionary patterns: the correlation structure of interspecific data. - Evolution 50: 1404-1417.

Jaenike, J. and Markow, T. A. 2003. Comparative elemental stoichiometry of ecologically diverse Drosophila. - Funct. Ecol. 17: $115-120$.

Kay, A. D. et al. 2005. Toward a stoichiometric framework for evolutionary biology. - Oikos 109: 6-17.

Markow, T. A. et al. 1999. Elemental stoichiometry of Drosophila and their hosts. - Funct. Ecol. 13: 78-84.

Martins, E. P. and Hansen, T. F. 1997. Phylogenies and the comparative method: a general approach to incorporating phylogenetic information into the analysis of interspecific data. - Am. Nat. 149: 646-667.

Martinson, H. M. et al. 2008. Detritivory: stoichiometry of a neglected trophic level. - Ecol. Res. 23: 487-491.

Mayntz, D. et al. 2005. Nutrient-specific foraging in invertebrate predators. - Science 307: 111-113.

Oosterbroek, P. 2006. The European families of the Diptera: identification, diagnosis, biology. - KNNV Publishing.

Paradis, E. et al. 2004. APE: analysis of phylogenetics and evolution in $\mathrm{R}$ language. (package available freely under the GNU General Public License at: <http://cran.r-project.org/ src/contrib/packages.html\#ape >). - Bioinformatics 20: 289290.

Perkins, M. C. et al. 2004. Dietary phosphorus affects the growth of larval Manduca sexta. - Arch. Insect Biochem. Physiol. 55: 153-168.

Raubenheimer, D. and Simpson, S. J. 1997. Integrative models of nutrient balancing: application to insects and vertebrates. - Nutr. Res. Rev. 10: 151-179.

Raubenheimer, D. et al. 2007. Nutrient-specific compensation following diapause in a predator: implications for intraguild predation. - Ecology 88: 2598-2608.

Schade, J. D. et al. 2003. Stoichiometric tracking of soil nutrients by a desert insect herbivore. - Ecol. Lett. 6: 96-101.

Sommaggio, D. 1999. Syrphidae: can they be used as environmental bioindicators? - Agr. Ecosyst. Environ. 74: 343-356.

Sterner, R. W. and Elser, J. J. 2002. Ecological stoichiometry: the biology of elements from molecules to the biosphere. - Princeton Univ. Press. 
Torp, E. 1984. De danske svirrefluer (Diptera: Syrphidae). Danmarks dyreliv, Bind 1. - Apollo Books.

Vrede, T. et al. 2004. Fundamental connections among organism $\mathrm{C}: \mathrm{N}: \mathrm{P}$ stoichiometry, macromolecular composition, and growth. - Ecology 85: 1217-1229.

Watts, T. et al. 2006. Biological stoichiometry of growth in Drosophila melanogaster. - J. Insect Physiol. 52: 187-193.

Woods, H. A. et al. 2003. Temperature and the chemical composition of poikilothermic organisms. - Funct. Ecol. 17: 237-245.

Supplementary material (available online as Appendix O17177 at www.oikos.ekol.lu.se/appendix). Table S1, Table S2, Table S3.
Woods, H. A. et al. 2004. Allometric and phylogenetic variation in insect phosphorus content. - Funct. Ecol. 18: 103-109. Yeates D. et al. 2006. FlyTree: phylogenetic supertree of Diptera (April 13 Dataset). Available online at: <http://www. inhs.uiuc.edu/research/FLYTREE/supertree.html $>$. 